\title{
Evaluation of a Humor Training for Patients with Chronic Pain: A Randomized Clinical Trial
}

\author{
Lisa Kugler' \\ Christof Kuhbandner' \\ Sarah Gerum ${ }^{2}$ \\ Christian Hierl $^{2}$ \\ Tino Münster ${ }^{2}$ \\ Bernadette Offereins ${ }^{3}$ \\ Lea Sophie Lutterbach' \\ 'Department of Psychology, University of \\ Regensburg, Regensburg, Germany; \\ ${ }^{2}$ Clinic for Anesthesia and Intensive Care \\ Medicine, Hospital Barmherzige Brüder, \\ Regensburg, Germany; ${ }^{3}$ Clinic for \\ Forensic Psychiatry and Psychotherapy, \\ Medbo District Hospital, Regensburg, \\ Germany
}

Correspondence: Christof Kuhbandner Department of Psychology, University of Regensburg, Regensburg, 93053, Germany

Email christof.kuhbandner@ur.de
Background: Humor and laughter are positively associated with psychological as well as with physical well-being. As there is little research examining to what extent patients suffering from chronic pain could benefit from a humor intervention, the goal of this study was to develop a pain-specific humor training and to evaluate its feasibility and effectiveness as component of regular, multimodal pain therapy.

Patients and Methods: Patients from inpatient treatment groups for chronic pain in a German hospital were randomly assigned to the training group (final $n=62$ ) and the control group (final $n=65$ ). The training consisted of four sessions that were implemented in the usual therapy throughout two weeks. Outcomes were divided into primary (perceived current pain intensity and depression) and secondary ones (quality of life impairment by pain, cheerfulness, and self-enhancing humor) and were assessed prior to and after intervention.

Results: Results showed improvements in all outcomes for both groups. For primary outcomes, a trend for a greater reduction in current pain intensity was found for the training group compared to the control group ( $p=0.060, \eta_{p}^{2}=0.02$ ), as well as, for secondary outcomes, a trend for greater reduction of quality of life impairment by pain $\left(p=0.079, \eta_{p}^{2}=\right.$ $0.02)$ and a trend for greater increase in self-enhancing humor $\left(p=0.086, \eta_{p}^{2}=0.02\right)$. Depression and cheerfulness remained unaffected. Feedback indicated feasibility of the training within multimodal therapy, showing overall acceptance as well as providing specific suggestions for improvement.

Conclusion: As the first study evaluating a specific humor training for patients with chronic pain within a randomized controlled trial, its results are promising regarding an additional contribution that humor interventions can make towards multimodal pain therapy.

Keywords: humor training, coping, positive psychology intervention, multimodal pain therapy

\section{Introduction}

Positive emotions build personal resources and resilience by enhancing an individual's thought and action repertoires, as the broaden-and-build theory postulates. ${ }^{1}$ Simultaneously, the lingering of negative emotions is alleviated. Therefore, in clinical research, the combination of reducing psychopathology and increasing positivity is discussed as an encouraging approach to foster psychological and physical health. One promising psychological mechanism in this respect that has gained increasing interest in recent research is humor. From the perspective of personality psychology, humor is considered being a beneficial character strength associated with subjective well-being and resilience, especially when having to deal with adverse life events. ${ }^{2,3}$ Therefore, in the recent years, more and more studies 
examined the effectiveness of humor interventions for patients suffering from psychological disorders, such as mainly depression, but also anxiety, schizophrenia, or adjustment disorder. ${ }^{4-7}$

However, to date, there is experimental and correlational evidence that humor and laughter increase pain tolerance, ${ }^{8-10}$ but methodologically reliable research addressing possible benefits of humor interventions for patients suffering from chronic pain is rare. As the biopsychosocial model of chronic pain suggests, pain is understood as a complex interaction of biological, psychological, as well as social factors. ${ }^{11}$ From this point of view, patients suffering from chronic pain might considerably benefit from the effects of humor and laughter on a variety of levels. It is suggested that humor might affect health due to the positive emotions that are elicited by humor and laughter, as there is evidence that positive emotions may have beneficial effects on nervous, endocrine and immune responses, as well as on their interactions concerning the experience of pain. ${ }^{12}$ These findings go along with the considerations about the effects humor might have on a psychological level. Research has shown that humor can help individuals to cope with adverse experiences, both emotionally and cognitively. Emotionally, humor might bring about an "undoing" of negative emotions by the elicitation of positive affective states. ${ }^{13}$ Cognitively, humor can shift the focus of attention away from the negative gist of an adverse experience, which can reduce the strength of elicited negative emotions. ${ }^{14}$ Indeed, some studies support the analgesic effect of humor due to distraction., 9 On the other hand, humor comes along with a reinterpretation of adverse experiences in less threatening ways, which can downregulate elicited negative emotions. ${ }^{16}$ In particular, since humor allows a perspective change while keeping distance from the adverse experience, downregulation by humorous reinterpretation may be more effective than downregulation by rational or positive reinterpretations. ${ }^{17-19}$ Finally, on the social level, humor and especially laughter can have a positive impact on social communication and interactivity. Laughing together with someone promotes greater positive emotions and intimacy and makes social interactions more enjoyable, why it may function as an important mechanism for strengthening social bonds. ${ }^{20,21}$ Since satisfying social relationships is one of the main factors contributing to physical and psychological well-being, humor may thus have a positive effect on the quality of life of pain patients, as they often withdraw from daily social activities, ${ }^{22}$ which increases loneliness and the potential risk for depression. ${ }^{23}$

Taken together, humor might help chronic pain patients to emotionally undo negative by positive emotions, to pay less attention to their pain as well as to cognitively view it as less negative and stressful. Finally, by counteracting detrimental effects of chronic pain at the level of social relationships, humor may help chronic pain patients to cope with their pain ${ }^{24}$ and, more generally, to maintain functional social interactions. ${ }^{25}$ Therefore, a humor training for patients with chronic pain seems promising in order to decrease pain experience and to increase their well-being and quality of life.

The general effectiveness of humor trainings has been proven in previous research, demonstrating an increase in positive outcomes regarding emotional well-being as well as a decrease in negative outcomes such as depressive symptoms. ${ }^{26-28}$ In mental healthcare settings, effectiveness of humor trainings could be especially shown in raising coping humor abilities, ${ }^{4,6}$ improving cheerfulness, satisfaction of life and resilience of older patients ${ }^{5,29}$ and, in a study with patients suffering from schizophrenia, in reducing depressive symptoms. ${ }^{4}$ Admittedly, it is important to note that intervention studies in this field often rely on rather small sample sizes or only quasi-experimental designs, or the effects were only compared to wait-list control groups rather than to active or treatment-as-usual control groups. ${ }^{30,31}$

Nevertheless, whereas studies examining effectiveness as well as feasibility of humor trainings are relatively well established for several mental disorders, ${ }^{6,7}$ humor trainings for patients with chronic pain are largely unexamined. To our knowledge, there are very few studies examining the effect of a humor therapy, showing a decrease in pain intensity for older adults. ${ }^{32,33}$ However, in these studies, humor therapy was evaluated through quasi-experimental designs in two different nursing homes each, and humor interventions were conceptualized without a pain-specific focus. The aim of the present study was to develop a comprehensive, theorybased humor training for chronic pain patients where the use of humor for coping with pain and pain-associated impairments is practiced, and to evaluate its feasibility and effectiveness within an in-patient, multimodal pain therapy. To overcome methodological limitations of past research, a randomized controlled trial design was used. The effect of the humor training was measured on primary and secondary pain-related as well as psychological well-being outcomes. Primary outcomes were the reduction of perceived pain intensity as well as depression, which commonly occurs 
together with painful symptoms and is recommended to be treated simultaneously in pain therapy. ${ }^{34}$ Secondary outcomes were the reduction of quality of life impairment by pain, cheerfulness, and self-enhancing humor as a coping ability, which was recently suggested to help in the adjustment of chronic pain through potentially facilitating the acceptance of pain as well as pain-related negative emotions. $^{35}$

\section{Patients and Methods Participants}

The study was approved by the ethics committee of the German Psychological Society (DGPs) and conducted in accordance with the Declaration of Helsinki. It was registered at the German Clinical Trials Register (DRKS00019195). The sample of the study was built by in-patients of a German clinic for anesthesiology and critical care, all providing written informed consent to participate in the study. Patient's main clinical picture was chronic pain disorder with somatic and psychological factors (ICD-10: F45.41). Exclusion criteria for participating in the study were severe cognitive impairments or linguistic difficulties. Rare decisions about exclusions of patients from the study were made by the treating physicians and psychologists before they handed out consent forms for the study. Moreover, analysis inclusion criterion for participants of the training group was attendance at three sessions of the training at least. Power analysis (using $G^{*}$ Power 3.1.7) ${ }^{36}$ revealed a requested sample-size of $\mathrm{N}=128$ to have sufficient power $(0.80$, alpha $=0.05)$ to detect small to medium-sized effects $(f=0.18)$. Figure 1 depicts a flowchart for an overview of the participants. The final sample for the pre-post-analysis of primary outcomes consisted of 62 participants in the training group ( 43 females, mean age $=61.56$ years, $\mathrm{SD}=14.73$ ) and 65 participants in the control group (44 females, mean age $=58.77$ years, $\mathrm{SD}=12.04)$. Most of the participants that had stated their highest education $(n=79)$ had finished secondary school (63.3\%). Groups did not differ in age, $t(124)=1.16$, $p=0.250$, gender, $\chi^{2}(1)=0.41, p=0.840$, and education, $\chi^{2}(8)$ $=5.53, p=0.700$.

\section{Outcomes}

Primary outcomes of the study were current pain intensity and depression as a co-morbidity of chronic pain disorder. Total scores of the scales were extracted from the German Pain Questionnaire (Deutscher Schmerzfragebogen DSF) ${ }^{37}$ that is commonly assessed and evaluated in pain therapy in Germany as well as by the present clinic, independently of this study. Current pain intensity was assessed through the Numeric Rating Scale (NRS), providing a scoring system between $0=$ no pain and $10=$ worst pain imaginable. Numerical rating scales have been shown to be reliable and valid measures of pain intensity and are commonly used in pain therapy and research. ${ }^{38}$ For examining the training's effect on depression, we selected the depression subscale of the German, short version of the Depression, Anxiety, and Stress Scales (DASS). ${ }^{39}$ Within seven items, the subscale reliably and validly captures the occurrence of a person's experiences of depression within the last week on a fourpoint Likert-scale from $0=$ did not apply to me at all to $3=$ did apply to me very much or most of the time. The depression subscale assesses the emotional state of depression without the confounding of somatic symptoms that are also associated with chronic pain disorder. ${ }^{39}$

Secondary outcomes of the study were life impairment by pain, cheerfulness, and self-enhancing humor. The Quality of Life Impairment by Pain Inventory (QLIP; DSF) $^{37}$ is used in the hospital ward to assess condition- and treatment-related changes of global impairment and general life quality within the last week. It contains seven items referring to general wellbeing (from $-100=$ very bad to $+100=$ very good), sufficient sleep duration (yes or no), continuous pain (yes or no), restrictions in activities and needs (fivepoint Likert-scale from $0=$ no to 4 = almost completely), impact on mood, and possibility of alleviating pain (each on a five-point Likert-scale from $0=$ no to $4=$ very much). Additionally, the inventory provides 11 other discomforts, such as sickness or vertigo, to mark with a cross. Items are counted up to a total value between $0=$ maximum impairment of life quality and 43 = no impairment of life quality. For a more intuitive use, we reversed the polarity of the total scores so that a higher value represents a higher impairment of life quality by pain. To measure exhilaration, the state version of the German State-Trait-Cheerfulness Inventory $(\mathrm{STCI}-\mathrm{S})^{40}$ was used. With 10 items each subscale, the state version reliably and validly assesses the sense of humor on a temperamental basis on the three dimensions cheerfulness (eg, "I am delighted"), seriousness (eg, "I am in a serious mind"), and bad mood (eg, "I feel downhearted") with a four-point Likert-scale from 1 $=$ totally disagree to $4=$ totally agree. $^{41}$ Internal consistencies (Cronbach's $\alpha$ ) for the three scales in this study were $0.91,0.79$, and 0.93 (pre-intervention). For measuring coping humor, we used the self-enhancing 


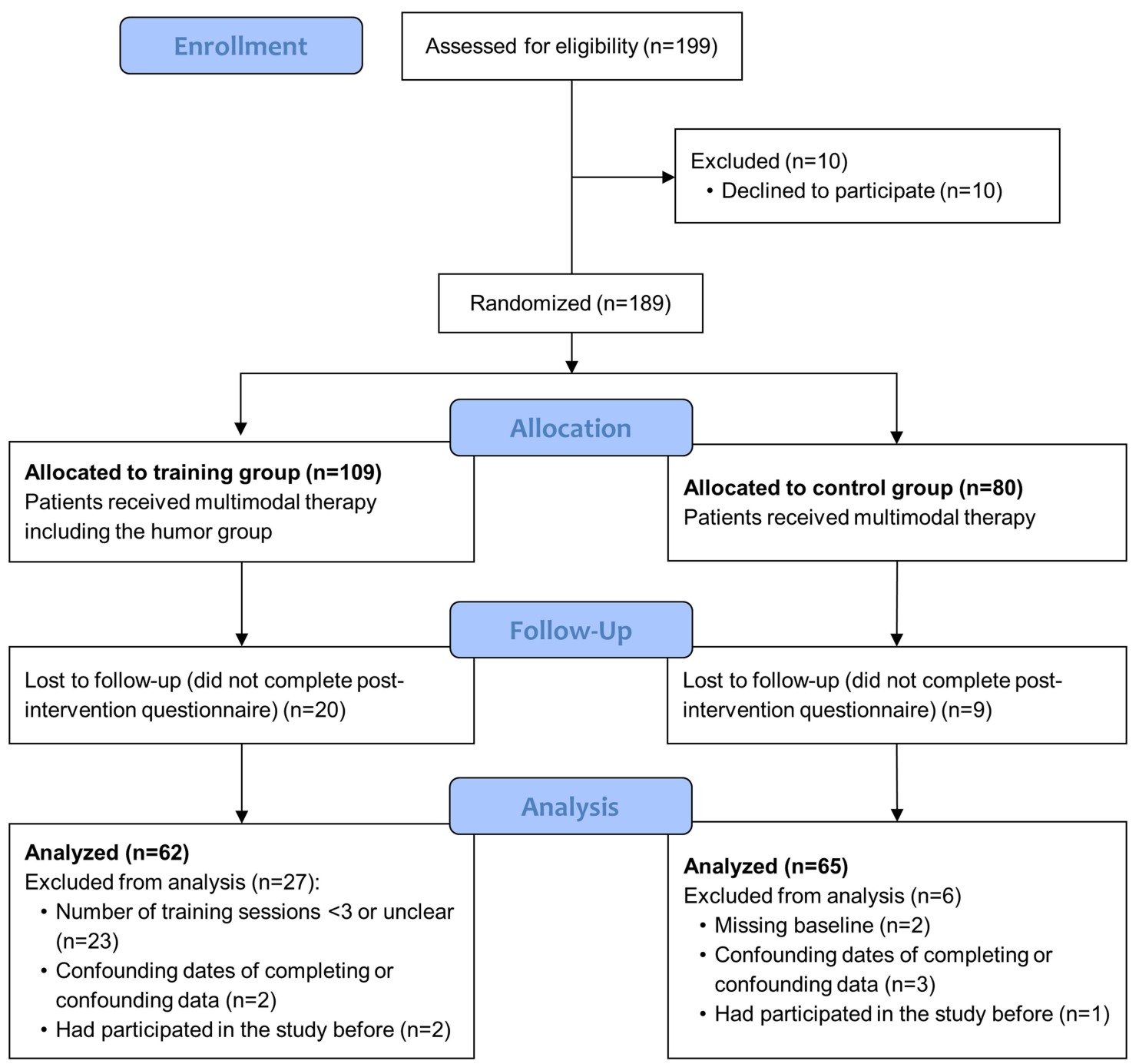

Figure I CONSORT flow diagram of the trial for primary outcomes.

humor subscale of the German version of the Humor Styles Questionnaire (HSQ), ${ }^{42}$ The subscale focusses on a humorous outlook on life and perspective-taking humor, relating to the tendency to use humor as emotion regulation or coping mechanism (eg, "If I am feeling upset or unhappy, I usually try to think of something funny about the situation to make myself feel better"). Items are rated on a seven-point Likert response scale from $1=$ totally disagree to $7=$ totally agree. The selfenhancing scale is strongly related to previous coping humor scales, providing a better reliability. ${ }^{42}$ Internal consistency (Cronbach's $\alpha$ ) in our study was 0.88 (preintervention). To examine differentiating research questions separately from the ones presented in this article, German versions of further scales were assessed throughout the study (Emotion Regulation Scale, ERQ; ${ }^{43}$ Positive And Negative Affect Schedule, PANAS; ${ }^{44}$ Generalized SelfEfficacy Scale, $\mathrm{SWE}^{45}$ ).

For the training group only, a feedback questionnaire was handed out to the participants, including 15 items covering a general evaluation of the training, impact on the use of humor, impact on perspective change, and expected impact on the future that should be rated on a seven-point Likert response scale from 1 = totally disagree to $7=$ totally agree. Additionally, the questionnaire included three open questions about what participants did like and did not like about the training, and what could be improved that could be answered without any given restrictions. 


\section{Design and Procedure}

The design of the study was a randomized controlled parallelgroup trial. Patients recruited in the time between January 2016 and August 2019 were randomly assigned to training or control groups when they began their stationary treatment. Training and control periods alternated depending on the trainer's availability as well as on vacation times of the clinical staff, but independently of any patient's characteristics. During a training period, the humor training was integrated into the standard, multimodal therapy that is conducted at the hospital ward. Filling out the questionnaires and therefore participating in the study, however, was on a voluntary basis and required the patients' consent. As the commitment to the training could have been affected by the term "training", potentially implying to the patients that they might not have a sense of humor yet, the program was usually called "humor group" within the hospital. Participants in the control group received regular multimodal pain therapy and were asked to complete questionnaires before and at the end of their in-patient stay on a voluntary basis in preparation for a humor group that they can attend after their stay. Accordingly, the chance for offering an equal treatment for all patients was ensured.

The training consisted of four modularized one-hour training sessions that were offered on four afternoons within a two-week period, as patients' length of stay was two to three weeks. The single modules were not consecutive, which enabled new patients to enter the program at any time. Usually, the training was attended by all the patients on the ward, which were eight at the maximum. The training was conducted by, in sum, seven master's students in psychology or chair's student associates which had experience in clinical practice and were instructed and trained by the study's leader intensively. After the last session (or after 14 days for the control group), participants were asked to complete the post-intervention questionnaires including the feedback questions for participants of the training group. For a second follow-up, questionnaires were again sent to the participants by mail three months after post-intervention assessment. However, these data were not included in this article, as response was too low to obtain valid results $(44.6 \%$ of the control group and $59.7 \%$ of the training group for primary outcomes).

\section{The Training}

The structure of the training was built with respect to the promising effects of humor, deriving presumptions about humor's potential to help handling chronic pain focusing on expressive (module 1), motivational (module 2), cognitive (module 3), and emotional (module 4) levels. Table 1 depicts an overview of the training sessions. Several exercises within the training were taken from the German manual by Falkenberg et $\mathrm{al}^{46}$, wich is a humor training program for the psychiatric and psychotherapeutic practice, based on the wellknown 7 Humor Habits Program by Paul $\mathrm{McGhee}^{47}$ to enhance humor as an ability for coping with life stress and to increase positive affect in everyday life. Those exercises were slightly adapted to the patient group as appropriate. Consequently, depending on the particular topic of the module, training sessions included psychoeducation about humor's strengths, physical and laughing practices, and creative tasks or exercises how to change perspective in a humorous way and to strengthen the positive things in life. Before new participants started their first session, they were introduced into structure and content of the training. Every session started with a warm-

Table I Overview of the Humor Training

\begin{tabular}{|l|l|l|l|}
\hline Module & Title & Aim & Content \\
\hline I & $\begin{array}{l}\text { Allowing } \\
\text { yourself to } \\
\text { laugh }\end{array}$ & $\begin{array}{l}\text { Encouraging the expression of joy and cheerfulness; } \\
\text { overcoming potential inhibitions }\end{array}$ & $\begin{array}{l}\text { Elaboration of functions and physical effects of laughter; } \\
\text { practices to experience laughter; playful exercises to "let } \\
\text { yourself go" }\end{array}$ \\
\hline 2 & $\begin{array}{l}\text { What humor } \\
\text { can do }\end{array}$ & $\begin{array}{l}\text { Imparting knowledge about the positive effects of } \\
\text { humor; enhancing the motivation to use humor as } \\
\text { a coping strategy }\end{array}$ & $\begin{array}{l}\text { Elaboration of the variety of positive effects of humor on well- } \\
\text { believes }\end{array}$ \\
\hline 3 & Rethinking & $\begin{array}{l}\text { Fostering the ability to see and evaluate situations } \\
\text { in new and humorous ways }\end{array}$ & $\begin{array}{l}\text { Creative, practical exercises to overcome habits and to look at } \\
\text { situations from a more humorous point of view }\end{array}$ \\
\hline 4 & $\begin{array}{l}\text { Giving humor } \\
\text { more space }\end{array}$ & $\begin{array}{l}\text { Embedding the content of the training in everyday } \\
\text { life; overcoming hindering emotions }\end{array}$ & $\begin{array}{l}\text { Individual "humor anamnesis"; discussion about inhibiting } \\
\text { emotions; creating individual plans for implementing positive } \\
\text { and humorous activities }\end{array}$ \\
\hline
\end{tabular}


up exercise and a review of the homework from last session if applicable, before the session's respective topic was introduced. At the end of every session, homework was assigned either in preparation for the next session or to integrate contents in the hospital routine that participants had learned before. Additionally, participants were given the opportunity to write or draw their personal most important take-away-messages of the session in a drawn suitcase that was handed out before. When they had finalized their last session, participants were offered to take a polaroid picture of the group that was handed out to them together with the "laughing list", a sheet covering recommended humorous books and movies, as well as with stickers displaying the training's most important contents to remember.

\section{Analysis}

For statistical analysis, we used IBM SPSS Statistics 25. Chi-square test was used for analyzing differences in categorical demographic data, and independent samples $t$-test was used for analyzing differences in continuous demographic data and baseline levels. For examining withingroup, between-group, and interaction effects, analysis of variance (ANOVA) with repeated measures was used without imputation methods, as well as t-tests for analyzing prepost differences for each group. As one-tailed tests were computed examining these effects, corresponding p-levels are listed as one-tailed p-levels in the result sections for primary and secondary outcomes. Effect sizes of main and interaction effects are depicted as $\eta_{p}^{2}$, and effect sizes for post-hoc t-tests as $d$. Levels of $\eta_{p}^{2}$ are categorized as small $\left(\eta_{p}^{2}=0.01\right)$, medium $\left(\eta_{p}^{2}=0.06\right)$, and large $\left(\eta_{p}^{2}=0.14\right)$, and levels of $d$ as small $(d=0.20)$, medium $(d=0.50)$, and large $(d=0.80)$ based on benchmarks suggested by Cohen. ${ }^{48}$

Closed-format questions of the feedback questionnaire were analyzed descriptively. Open format questions were analyzed within qualitative analysis in MAXQDA2020. Patients' responses were inductively categorized and rated through two independent raters. Intercoder reliability was $\kappa$ $=0.73$, which is pointing to a substantial agreement. ${ }^{49}$

\section{Results}

\section{Preliminary Analysis}

Table 2 shows descriptive statistics of pre- and postintervention assessments of all outcomes for both the training and the control group. Training and control group did neither differ in their baseline levels of primary outcomes, current pain intensity, $t(119)=-0.43, p=0.668$, $d=0.08,95 \%$ CI: $-0.90-0.58$, depression $t(123)=0.67$, $p=0.505, d=0.12,95 \% \mathrm{CI}:-1.31-2.64$, nor in their baseline levels of secondary outcomes, quality of life impairment by pain, $t(118)=-0.77, p=0.222, d=0.14$, 95\% CI: $-3.72-1.64$, cheerfulness, $t(101)=-0.21$, $p=0.836, d=0.04,95 \% \mathrm{CI}:-0.28-0.23$, seriousness, $t$ $(101)=0.33, p=0.740, d=0.07,95 \% \mathrm{CI}:-0.17-0.25$, and bad mood, $t(101)=0.64, p=0.521, d=0.13,95 \% \mathrm{CI}$ : $-0.20-0.38$, as well as self-enhancing humor, $t(102)=$ $0.66, p=0.0 .513, d=0.13,95 \%$ CI: $-0.35-0.69$.

Table 2 Means, Standard Deviations, and Effect Sizes of Primary and Secondary Outcomes for Training and Control Group

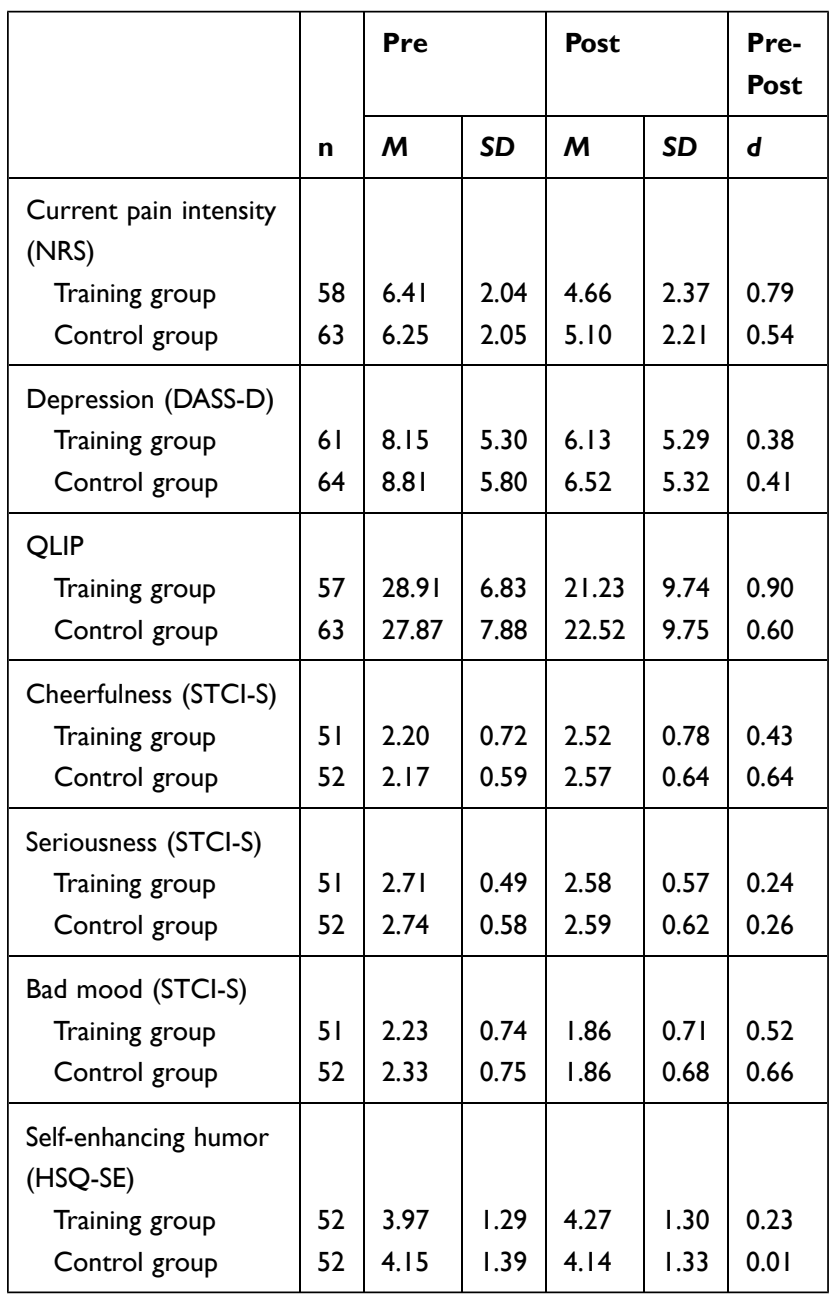

Note: Differences in noccur as not all scales have been completed by every participant. As the scales for secondary outcomes STHI-S and HSQ-SE were not included in the German Pain Questionnaire and were handed and filled out separately, a smaller sample resulted for these outcomes. Participants that only had completed secondary outcomes $(n=7)$ were not included in the quantitative analyses.

Abbreviations: DASS, Depression, Anxiety, and Stress Scales; HSQ-SE, selfenhancing subscale of the Humor Styles Questionnaire; NRS, Numeric Rating Scale; QLIP, Quality of Life Impairment by Pain Inventory; STCI-S, State-TraitCheerfulness Inventory - state version. 


\section{Primary Outcomes}

Table 3 shows main effects and group-by-time interaction of the ANOVA for repeated measures for the training and the control groups. ANOVA showed no main effects of group for current pain intensity and depression. Main effects of time were found for both of the primary outcomes, and a trend for an interaction of time by group was found for current pain intensity, $F(1,119)=2.45, p=0.060, \eta_{p}^{2}=$ 0.02 , indicating a change in current pain intensity with a small effect size depending on the group. T-tests showed that current pain intensity decreased in both groups, but stronger in the training group, $t(57)=5.24, p<0.001, d=$ $0.79,95 \%$ CI: 2.43 to 5.24 , than in the control group, $t(62)=$ 5.83, $p<0.001, d=0.54,95 \%$ CI: 0.76 to 1.56 . For depression, there was no interaction of time by group found, $F(1,123)=0.11, p=0.369, \eta_{p}^{2}=0.00$.

\section{Secondary Outcomes}

There were no main effects found of group for all of the secondary outcomes, but main effects of time were significant for all of the secondary outcomes (with only a trend for self-enhancing humor). For QLIP, there was a trend for an interaction of time by group, $F(1,118)=2.03 p=0.079, \eta^{2}$ $=0.02$, indicating a change in quality of life impairment by pain with a small effect size depending on the group. T-tests showed a decrease of impairment in both groups, which was stronger in the training group, $t(56)=6.22, p<0.001, d=$ $0.90,95 \%$ CI: 5.21 to 10.16 , than in the control group, $t$ (62) $=4.92, p<0.001, d=0.60,95 \% \mathrm{CI}: 3.17$ to 7.52 . There was also a trend for an interaction of time by group for selfenhancing humor, $F(1,102)=1.90, p=0.086, \eta_{p}^{2}=0.02$, indicating a change in the use of self-enhancing humor with a small effect size depending on the group. T-tests showed that self-enhancing humor only increased in the training group, $t(51)=-2.17, p=0.017, d=0.23,95 \% \mathrm{CI}:-0.57$ to -0.02 , but not in the control group, $t(51)=0.05, p=$ $0.482, d=0.01,95 \% \mathrm{CI}:-0.34$ to 0.36 . No interaction effects of time by group were found for cheerfulness, $F(1$, 101) $=0.28, p=0.230, \eta_{p}^{2}=0.00$, seriousness, $F(1,101)=$ $0.06, p=0.403, \eta_{p}^{2}=0.00$, and bad mood, $F(1,101)=0.48$, $p=0.245, \eta_{p}^{2}=0.01$.

\section{Feedback}

In total, $n=52$ participants of the training group completed most items of the feedback questionnaire. Overall, participants liked the training $(M=5.62, S D=1.55 ; 1=$ totally disagree, $7=$ totally agree), could benefit from it generally ( $M=5.31, S D=1.49)$ and would recommend the training to other pain patients $(M=5.50, S D=1.77)$. All of the other items, concerning the training's impact on the use of humor, on perspective change, and on the future perspectives were slightly weaker, but still above the scale midpoint. Results of the feedback questionnaire are summarized in Table 4.

Similar to Tagalidou et al, ${ }^{7}$ qualitative analysis of the open format questions was conducted for each of the three questions separately. The question about what participants liked about the training (positive aspects of the training, see Table 5) was answered by 40 participants, resulting in 55 coded statements. Most statements could be categorized as positive effects of the training $(\mathrm{n}=11)$, which were mainly perspective change $(n=3)$, increase of humor or laughter $(\mathrm{n}=3)$, but also increase in knowledge $(\mathrm{n}=2)$, or less pain $(\mathrm{n}=1)$. Participants also highlighted laughter and silliness during the training $(\mathrm{n}=10)$, characteristics of the trainer $(n=9)$ and specific contents of the training $(n=9)$ such as videos $(\mathrm{n}=2)$ and single exercises. $\mathrm{N}=6$ stated that they liked everything about the training. The question about what participants did not like about the training

Table 3 Main Effects and Group by Time Interaction for Training vs Control Group

\begin{tabular}{|c|c|c|c|c|c|c|c|}
\hline & \multirow[b]{2}{*}{$d f$} & \multicolumn{2}{|c|}{ Group } & \multicolumn{2}{|l|}{ Time } & \multicolumn{2}{|c|}{ Group by Time } \\
\hline & & $\boldsymbol{F}$ & $\eta_{p}^{2}$ & $\boldsymbol{F}$ & $\eta_{p}^{2}$ & $\boldsymbol{F}$ & $\eta_{p}^{2}$ \\
\hline Current pain intensity (NRS) & 1,119 & 0.17 & 0.00 & $58.03 * * *$ & 0.33 & $2.45^{\dagger}$ & 0.02 \\
\hline Depression (DASS-D) & 1,123 & 0.36 & 0.00 & $27.03 * * *$ & 0.18 & 0.11 & 0.00 \\
\hline QLIP & 1,118 & 0.01 & 0.00 & $63.16 * * *$ & 0.35 & $2.03^{\dagger}$ & 0.02 \\
\hline Cheerfulness (STCI-S) & $\mathrm{I}, \mathrm{I0I}$ & 0.01 & 0.00 & $27.5 \mathrm{I} * * *$ & 0.21 & 0.28 & 0.00 \\
\hline Seriousness (STCI-S) & 1,101 & 0.00 & 0.00 & $7.96 * *$ & 0.07 & 0.06 & 0.00 \\
\hline Bad mood (STCl-S) & $\mathrm{I}, \mathrm{I0I}$ & 0.14 & 0.00 & $38.86 * * *$ & 0.28 & 0.48 & 0.01 \\
\hline Self-enhancing humor (HSQ-SE) & $\mathrm{I}, 102$ & 0.01 & 0.00 & $1.70^{\dagger}$ & 0.02 & $1.90^{\dagger}$ & 0.02 \\
\hline
\end{tabular}

Notes: ${ }^{\dagger} p \leq 0.10,{ }^{* *} p<0.01,{ }^{* * *} p \leq 0.001$ (one tailed).

Abbreviations: DASS, Depression, Anxiety, and Stress Scales; HSQ-SE, self-enhancing subscale of the Humor Styles Questionnaire; NRS, Numeric Rating Scale; QLIP, Quality of Life Impairment by Pain Inventory; STCI-S, State-Trait-Cheerfulness Inventory - state version. 
Table 4 Means and Standard Deviations of Feedback Items for Participants of the Training Group $(n=52)$

\begin{tabular}{|l|l|l|}
\hline & M & SD \\
\hline General evaluation of the training & & \\
Enjoyment of the training & 5.62 & 1.55 \\
Doing the training's homework & 4.76 & 1.89 \\
General benefit from the training & 5.31 & 1.49 \\
Anticipation of positive effects of the training before & 4.69 & 1.58 \\
Recommendation of the training to other pain & 5.50 & 1.77 \\
patients & & \\
\hline Training's impact on the use of humor & & \\
More use of humor in different situations & 4.94 & 1.46 \\
Greater knowledge of the effects of humor & 4.84 & 1.76 \\
Less hesitation to laugh openly & 4.50 & 1.79 \\
Less doubt about making fun of things & 3.96 & 1.71 \\
\hline Training's impact on perspective change & & \\
Changed perspective on life in a positive way & 4.73 & 1.67 \\
Changed perspective on symptoms in a positive way & 4.55 & 1.63 \\
Easier humorous reframing of situations & 4.55 & 1.54 \\
Viewing pain in a more humorous manner & 4.29 & 1.84 \\
\hline Training's impact on the future & & \\
Long-term positive effects on overall quality of life & 4.69 & 1.52 \\
Intention to apply the strategies in everyday life & 5.02 & 1.50 \\
\hline
\end{tabular}

Notes: $\mathrm{I}$ = totally disagree, 7 = totally agree.

(negative aspects of the training) was answered by 26 participants, resulting in 27 coded statements. Concerning content of the training $(\mathrm{n}=10)$, participants mainly criticized that it was too theoretical $(n=2)$ and that serious topics were mentioned $(n=2)$. Among other aspects, group-related factors $(\mathrm{n}=3)$ as well as time or long duration of the sessions $(n=3)$ were mentioned as negative. $\mathrm{N}=4$ stated that there were no negative aspects about the training. Suggestions for potential improvements were made by 27 participants, resulting in 35 coded statements. Patient's suggestions concerning content of the training $(\mathrm{n}=12)$ mostly included less theory $(\mathrm{n}=3)$ and more funny videos $(n=2)$ and jokes $(n=2)$. Other participants wished more humor, laughter or playfulness in general $(n=4)$. It was recommended to improve premises $(n=4)$, and that sessions were not held in the late afternoon or/and for a whole hour $(n=3)$, but some of the participants also wished to have more sessions $(n=3)$.

Table 5 shows further mentioned aspects as well as the number of codings for each question and in each category. Categories "others" contained statements about the questionnaires, clinical treatment, or that participants had nothing to say.
Table 5 Codings for Answers on Open Feedback Questions by Participants of the Training Group $(n=43)$

\begin{tabular}{|c|c|}
\hline & $\begin{array}{l}\text { Number of } \\
\text { Codings in } \\
\text { Category }\end{array}$ \\
\hline Positive aspects of the training $(n=40)$ & 55 \\
\hline Effects of the training & $\mathrm{II}$ \\
\hline Laughter and silliness during the training & 10 \\
\hline Content of the training & 9 \\
\hline Characteristics of the trainer & 9 \\
\hline Everything & 6 \\
\hline Group (atmosphere and communication) & 4 \\
\hline Setting & 2 \\
\hline Hardly any & 2 \\
\hline Others & 2 \\
\hline Negative aspects of the training $(n=26)$ & 28 \\
\hline Content of the training & 10 \\
\hline No negative aspects & 4 \\
\hline Group (communication and constellation) & 3 \\
\hline Time/duration of the sessions & 3 \\
\hline Characteristics of the trainer & 2 \\
\hline Practicability & I \\
\hline Premises & I \\
\hline Others & 4 \\
\hline Potential improvements of the training $(n=27)$ & 35 \\
\hline Content of the training & 12 \\
\hline More humor/laughter/playfulness & 4 \\
\hline Better premises & 4 \\
\hline More sessions & 3 \\
\hline Other time of day/duration & 3 \\
\hline No need for improvement & 3 \\
\hline Larger group size & I \\
\hline Others & 5 \\
\hline
\end{tabular}

Notes: Statements of all participants that had visited one or more training sessions and filled out the feedback questionnaire were included in qualitative analysis. Only one of them was excluded as this patient had participated in the study before. $\mathrm{N}=$ 32 visited at least three sessions of the training.

\section{Discussion}

The aim of this study was to evaluate effectiveness and feasibility of a humor training for patients with chronic pain as part of their in-patient, multimodal pain therapy. Compared to the treatment-as-usual control group, the training group showed a stronger reduction in pain perception and quality of life impairment, and a stronger increase in the use of coping humor through self-enhancement. Depression and cheerfulness remained unaffected by the training. The patient's feedback showed feasibility and acceptance of the training. Participants overall liked the training, and, for instance, their emphasis on special effects of the training as well as the enjoyment of humor 
and laughter especially in the group indicates appreciation and subjective benefit from the training for a variety of participants. However, they also indicated some aspects that could be improved regarding content, for instance, including more funny and playful components, but also regarding framework conditions, such as premises as well as time and duration of the training sessions.

To our knowledge, this is the first study examining the effects of a humor training within a randomized controlled trial for patients with chronic pain. Considering the control group receiving multimodal therapy likewise, finding additional effects of the training, even if small, is remarkable. Therefore, these small effects might be important indicators of the reasonableness of a humor training to be implemented in multimodal pain therapy. In particular, it is important to note that pain was not measured shortly after the sessions, which was apparently done in previous studies on the effects of humor therapy on chronic pain in the elderly, ${ }^{32,33}$ also finding a reduction in perceived pain. In this study, participants completed the questionnaires between the last training session and discharge from hospital, which could be up to seven days after. Finding an effect of humor under such conditions is really promising, as this suggests that the effects of the humor training are relatively long-lasting, although long-term effects for months still have to be examined.

The training potentially improved self-enhancing humor as a coping ability, which is considerable due to its promising role that it possibly plays in the adjustment of chronic pain. ${ }^{35}$ Interestingly, we could not find any additional effects of the training for the improvement of cheerfulness. This is in contrast to findings of previous studies evaluating humor trainings in the clinical context, for instance, by Tagalidou et al. ${ }^{6}$ Also, missing effects of the training on depression might seem surprising on first sight, as there were several indications in previous literature that humor interventions can have a positive impact on depression in clinical as well as in non-clinical samples. ${ }^{4,28}$ However, an explanation for these missing effects might concern the content and focus of the training. The aim of our training was to strengthen humor in a more comprehensive sense, including a humorous outlook on adverse life events and circumstances, which requires to also address these topics in the sessions. Our training also included lots of discussions, presentations and exercises in order to gain insights about the functions of humor while focusing less on just the elicitation of positive emotions. To address depressive symptoms and also cheerfulness, probably humor trainings should focus more on positive emotional experiences than on cognitive aspects, which was also reviewed by some of the participants themselves within the open feedback questions, suggesting more funny content or laughter and playfulness in general for improvement of the training. This is in line with a study examining the working mechanism of pleasure-based positive psychology interventions by Gander et $\mathrm{al}^{50}$ revealing that it precisely was elicited positive emotions (intervention with emotional focus) that mediated the effects of these interventions on depressive symptoms and happiness, while gained insights (intervention with cognitive focus) only mediated the effects on happiness. This is also supported by the results of studies in the treatment of depression, indicating that positive psychology interventions help reducing symptoms and preventing of relapses by developing personal strengths through especially the increase of positive emotions. ${ }^{51}$ Whether a humor training group might also have long-term benefits by helping to decrease the risk of recurrence in depression may therefore be examined in future intervention studies with emotion focused humor interventions and long-term follow-ups.

Similarly, it might be of interest to examine the differential effects of humor, seen as a predominantly cognitive process, and laughter as a physical behavior on outcomes associated with chronic pain, as they do not necessarily occur together. ${ }^{52}$ There indeed is some evidence that also laughter only therapies might be effective in increasing well-being and also in reducing pain for different patient populations. ${ }^{31,53}$ In the present study, patients often laughed in the training sessions, especially in module 1 (allowing yourself to laugh), but frequency and duration of laughter were not documented or measured individually, which would be necessary to build evidence for the benefit of laughter. ${ }^{54}$ Whereas the aim of this study was to evaluate a comprehensive humor training based on a theoretically justified model containing expressive, motivational, cognitive, and emotional aspects of humor as a coping strategy for handling chronic pain, future studies on humor interventions in this area should also examine the different effects of humor and laughter on chronic pain, promoting a better understanding of the benefits of these interventions for chronic pain patients.

Following the feedback of the patients, future humor interventions following the one in this study could be adapted to further improve suitableness and raise 
commitment of patients with chronic pain, considering, eg, less theoretical and more funny content, more laughter and playfulness, and shorter time slots than an hour which take place earlier than late afternoon. However, feedback might be strongly depending on the sample of a training study, which is why this is not generalizable for all patient populations. Also, interpreting the results of the study, one has to take the heterogeneity of this study's sample into consideration. Participants suffered from different types of pain and potential psychiatric comorbidities which were not documented in this study. According to the different feedback and the trainers' reports, content of the training, such as exercises, jokes, and the imparting of knowledge, was received differently by the participants. This leads to the question who generally might benefit from a humor intervention, especially in clinical contexts. There is some research about the potential role of personality traits moderating the benefit of humor interventions, suggesting that extraversion and trait cheerfulness predict how much individuals benefit from such an intervention, ${ }^{55-57}$ but research is necessary how specific clinical symptoms may moderate the benefit of a humor intervention to evaluate how suitable humor trainings may be for different clinical subgroups.

However, for patients suffering from chronic pain, the findings of our study show the potential of a humor training complementing psychological elements within multimodal therapy by imparting additional strategies for active pain management. Therefore, humor should be considered as an integral aspect of pain therapy, although investigations into long-term effects of humor interventions for patients suffering from chronic pain are required to evaluate lasting benefits. Additionally, as mentioned in the method section, it should be empirically examined whether there indeed is an overall better acceptance when a humor program is called "humor group" instead of "humor training", as the term "training" might be discouraging implying upcoming work or that a deficit in humor skills is assumed.

\section{Limitations}

It is notable about the results of our study that there were still additional effects of the humor training, despite the training group was compared to a treatment-as-usual control group. However, these effects were rather small, and could only have been determined with a level of significance below 0.10 . This demonstrates that, within a design including a control group as it was done in this study, larger sample sizes are necessary to demonstrate significant effects.

Additionally, a longer or more frequent intervention could probably reveal larger effects than the one we could find in our study. However, as the in-patient treatment, the training was implemented in, usually lasted only for two to three weeks and only two time slots per week were feasible, we needed to conduct a humor training in a very short time instead of a period of four or even eight weeks that usually is intended for humor interventions based on the 7 Humor Habits Program. ${ }^{47}$ A more frequent training program would also not have been reasonable for the patients in this study, as many of them appeared to be very exhausted after a few therapy units. However, we assume that four sessions, respectively two weeks, of training might be too little to make big steps that are statistically detectable. Research is necessary that systematically explores the length and frequency of humor training programs. ${ }^{58}$ However, stationary pain therapy usually is provided considerably shorter than eight weeks (see, eg, the German procedure classification ${ }^{59}$ ) why the results of our study still are encouraging for using the training as an effective additional intervention mitigating pain-related symptoms also within shorter treatments.

Missing documentary or not transmitted information about the participants due to the cooperation of two institutions and organizational difficulties is another considerable shortcoming of the study. Therefore, diagnoses and medication were not documented in this study. Additionally, due to communication gaps, reasons for skipping sessions or drop out by participants, which was relatively high in this study, could mostly not be reproduced. Reasons for drop out also were shorter treatments or moving to other wards, why comparisons between completers and non-completers would have been ineffectual.

\section{Conclusion}

This study was the first evaluating a humor training within multimodal pain therapy by a randomized controlled trial design. The study revealed the potential of a comprehensive humor training to make an additional contribution to therapy for chronic pain, demonstrated its feasibility, and provided suggestions by the patients for improvement. Larger sample sizes are needed to gain statistically reliable results, and future research should investigate in the potential role of personality, long-term effects, and length as well as frequency of humor training programs in pain therapy. So far, the training evaluated in 
this study provides valuable indications to bring laughter and humor back to people suffering from chronic pain.

\section{Data Sharing Statement}

Datasets are available to qualified researchers by reasonable request from the corresponding author during the year after the publication of this article.

\section{Acknowledgments}

For leading the training sessions and supporting us conducting the study, we want to thank Julia Argauer, Sophia Beck, Linda Breinbauer, Amelie Effelsberg, Magdalena Hamann, Laura Jonas, and Luise Schulz. Thanks are also due to Kathrin Ingerl, Karin Kefer, and Alina Rücker, who assisted us in the data collection, and Yvonne Metzl for her assistance in coding the open format feedback. Not least, we would like to thank all the patients that participated in the study.

\section{Disclosure}

The authors report no conflicts of interest in this work.

\section{References}

1. Fredrickson BL, Huppert FA, Baylis N, Keverne B. The broaden-andbuild theory of positive emotions. Philos Trans R Soc Lond B Biol Sci. 2004;359:1367-1377. doi:10.1098/rstb.2004.1512

2. Kuiper NA. Humor and resiliency: towards a process model of coping and growth. Eur J Psychol. 2012;8(3):475-491. doi:10.5964/ ejop.v8i3.464

3. Papousek I. Humor and well-being: a little less is quite enough. Humor. 2018;31(2):311-327. doi:10.1515/humor-2016-0114

4. Cai C, Yu L, Rong L, Zhong H. Effectiveness of humor intervention for patients with schizophrenia: a randomized controlled trial. J Psychiatr Res. 2014;59:174-178. doi:10.1016/j.jpsychires.2014.09.010

5. Konradt B, Hirsch RD, Jonitz MF, Junglas K. Evaluation of a standardized humor group in a clinical setting: a feasibility study for older patients with depression. Int J Geriatr Psychiatry. 2013;28 (8):850-857. doi:10.1002/gps.3893

6. Tagalidou N, Faschingbauer M, Mussuros T, Ruch W, Laireiter A-R. Effectiveness and feasibility of a humor training in a routine care setting for people suffering from mental disorders. Humor. 2019;32 (3):449-473. doi:10.1515/humor-2018-0006

7. Tagalidou N, Distlberger E, Loderer V, Laireiter AR. Efficacy and feasibility of a humor training for people suffering from depression, anxiety, and adjustment disorder: a randomized controlled trial. $B M C$ Psychiatry. 2019;19(1):1-13. doi:10.1186/s12888-019-2075-x

8. Dunbar RIM, Baron R, Frangou A, et al. Social laughter is correlated with an elevated pain threshold. Proc R Soc B Biol Sci. 2012;279 (1731):1161-1167. doi:10.1098/rspb.2011.1373

9. Weisenberg M, Tepper I, Schwarzwald J. Humor as a cognitive technique for increasing pain tolerance. Pain. 1995;63(2):207-212. doi:10.1016/0304-3959(95)00046-U

10. Zweyer K, Velker B, Ruch W. Do cheerfulness, exhilaration, and humor production moderate pain tolerance? A FACS study. Humor. 2004;17(1-2):85-119. doi:10.1017/CBO9781107415324.004
11. Gatchel RJ, Peng YB, Peters ML, Fuchs PN, Turk DC. The biopsychosocial approach to chronic pain: scientific advances and future directions. Psychol Bull. 2007;133(4):581-624. doi:10.1037/00332909.133.4.581

12. Hanssen MM, Peters ML, Boselie JJ, Meulders A. Can positive affect attenuate (persistent) pain? State of the art and clinical implications. Curr Rheumatol Rep. 2017;19(12). doi:10.1007/s11926-017-0703-3

13. Fredrickson BL, Mancuso RA, Branigan C, Tugade MM. The undoing effect of positive emotions. Motiv Emot. 2000;24(4): 237-258. doi: 10.1023/A:1010796329158

14. Strick M, Holland RW, van Baaren RB, van Knippenberg A. Finding comfort in a joke: consolatory effects of humor through cognitive distraction. Emotion. 2009;9(4):574-578. doi:10.1037/a0015951

15. Mitchell LA, MacDonald RAR, Brodie EE. A comparison of the effects of preferred music, arithmetic and humour on cold pressor pain. Eur J Pain. 2006;10(4):343-351. doi:10.1016/j.ejpain.2005.03.005

16. Samson AC, Gross JJ. Humour as emotion regulation: the differential consequences of negative versus positive humour. Cogn Emot. 2012;26(2):375-384. doi:10.1080/02699931.2011.585069

17. Braniecka A, Hanć M, Wołkowicz I, Chrzczonowicz-Stępień A, Mikołajonek A, Lipiec M. Is it worth turning a trigger into a joke? Humor as an emotion regulation strategy in remitted depression. Brain Behav. 2019;9(2):e01213. doi:10.1002/brb3.1213

18. Kugler L, Kuhbandner C. That's not funny! - but it should be: effects of humorous emotion regulation on emotional experience and memory. Front Psychol. 2015;6:1296. doi:10.3389/fpsyg.2015.01296

19. Samson AC, Glassco AL, Lee IA, Gross JJ. Humorous coping and serious reappraisal: short-term and longer-term effects. Eur J Psychol. 2014;10(3):571-581. doi:10.5964/ejop.v10i3.730

20. Kashdan TB, Yarbro J, McKnight PE, Nezlek JB. Laughter with someone else leads to future social rewards: temporal change using experience sampling methodology. Pers Individ Dif. 2014;58 (3):15-19. doi:10.1016/j.paid.2013.09.025

21. Manninen S, Tuominen L, Dunbar RI, et al. Social laughter triggers endogenous opioid release in humans. $J$ Neurosci. 2017;37 (25):6125-6131. doi:10.1523/JNEUROSCI.0688-16.2017

22. Dueñas M, Ojeda B, Salazar A, Mico JA, Failde I. A review of chronic pain impact on patients, their social environment and the health care system. J Pain Res. 2016;9:457-467. doi:10.2147/JPR. S105892

23. Joiner T Jr, Lewinsohn PM E, Seeley JR. The core of loneliness: lack of pleasurable engagement-more so than painful disconnection-predicts social impairment, depression onset, and recovery from depressive disorders among adolescents. J Pers Assess. 2002;79 (3):472-491. doi:10.1207/S15327752JPA7903_05

24. Sturgeon JA, Zautra AJ. Social pain and physical pain: shared paths to resilience. Pain Manag. 2016;6(1):63-74. doi:10.2217/pmt.15.56

25. Pérez-Aranda A, Hofmann J, Feliu-Soler A, et al. Laughing away the pain: a narrative review of humour, sense of humour and pain. Eur J Pain (United Kingdom). 2018;23(2):220-233. doi:10.1002/ejp.1309

26. Crawford SA, Caltabiano NJ. Promoting emotional well-being through the use of humour. J Posit Psychol. 2011;6(3):237-252. doi:10.1080/17439760.2011.577087

27. Ganz FD, Jacobs JM. The effect of humor on elder mental and physical health. Geriatr Nurs (Minneap). 2014;35(3):205-211. doi:10.1016/j.gerinurse.2014.01.005

28. Wellenzohn S, Proyer RT, Ruch W. How do positive psychology interventions work? A short-term placebo-controlled humor-based study on the role of the time focus. Pers Individ Dif. 2016;96:1-6. doi:10.1016/j.paid.2016.02.056

29. Hirsch RD, Junglas K, Konradt B, Jonitz MF. Humortherapie bei alten Menschen mit einer Depression: Ergebnisse einer empirischen Untersuchung [Humor therapy in elderly people with depression: results of an empirical study]. Z Gerontol Geriatr. 2010;43 (1):42-52. German. doi:10.1007/s00391-009-0086-9 
30. Gelkopf M. The use of humor in serious mental illness: a review. Evidence-Based Complement Altern Med. 2011;2011:34283. doi:10.1093/ecam/nep106

31. van der Wal CN, Kok RN. Laughter-inducing therapies: systematic review and meta-analysis. Soc Sci Med. 2019;232:473-488. doi:10.1016/j.socscimed.2019.02.018

32. Behrouz S, Mazloom SR, Kooshiar H, Aghebati N, Asgharipour N, Vashani HRB. Investigating the effect of humor therapy on chronic pain in the elderly living in nursing homes in mashhad, Iran. Evid Based Care J. 2017;7(2):27-36. doi:10.22038/EBCJ.2017.24247.1529

33. Tse MMY, Lo APK, Cheng TLY, Chan EKK, Chan AHY, Chung HSW. Humor therapy: relieving chronic pain and enhancing happiness for older adults. J Aging Res. 2010;2010. doi:10.4061/ 2010/343574.

34. Bair MJ, Robinson RL, Katon W, Kroenke K. Depression and pain comorbidity. Arch Intern Med. 2003;163(20):2433-2445. doi:10.1001/archinte.163.20.2433

35. Ramírez-Maestre C, Esteve R, López-Martínez AE, Miró J, Jensen MP, de la Vega R. Beyond pain intensity and catastrophizing: the association between self-enhancing humour style and the adaptation of individuals with chronic pain. Eur J Pain (United Kingdom). 2020;24(7):1357-1367. doi:10.1002/ejp.1583

36. Faul F, Erdfelder E, Lang A-G, Buchner A. G*Power 3.1 (manual): a flexible statistical power analysis program for the social, behavioral, and biomedical sciences. Behav Res Methods. 2014;39(2):78. doi:10.3758/BF03193146

37. Nagel B, Pfingsten M, Lindena G, Nilges P. Deutscher Schmerz-Fragebogen - Handbuch[German Pain Questionnaire Handbook]; 2012. Available from: http://docplayer.org/6456323Handbuch-dsf-deutscher-schmerz-fragebogen-april-2012-deutscherschmerz-fragebogen-handbuch.html. Accessed February 28, 2021. German.

38. Jensen MP, Karoly P. Self-report scales and procedures for assessing pain in adults. In: Turk DC, Melzack R, editors. Handbook of Pain Assessment. 2nd ed. Guilford Press; 2001:15-34.

39. Nilges P, Essau C. Die Depressions-Angst-StressSkalen [The Depression Anxiety Stress Scales]. Der Schmerz. 2015;29(6):649-657. German. doi:10.1007/s00482-015-0019-z

40. Ruch W, Köhler G, Van Thriel C. To be in good or bad humour: construction of the state form of the State-Trait-CheerfulnessInventory-STCI. Pers Individ Dif. 1997;22(4):477-491. doi:10.1016/ S0191-8869(96)00231-0

41. Ruch W, Hofmann J. A temperament approach to humor. In: Gremigni P, editor. Humor and Health Promotion. Nova Science Publishers; 2012:79-113.

42. Ruch W, Heintz S. The German version of the Humor Styles Questionnaire: psychometric properties and overlap with other styles of humor. Eur J Psychol. 2016;12(3):434 455. doi:10.5964/ejop.v12i3.1116

43. Abler B, Kessler H. Emotion Regulation Questionnaire - eine deutschsprachige Fassung des ERQ von Gross und John [Emotion Regulation Questionnaire - A German version of the ERQ by Gross and John]. Diagnostica. 2009;55(3):144-152. German. doi:10.1026/ 0012-1924.55.3.144

44. Krohne HW, Egloff B, Kohlmann C-W, Tausch A. Untersuchung mit einer deutschen Form der "Positive and Negative Affect Schedule" (PANAS) [Investigation with a German version of the "Positive and Negative Affect Schedule" (PANAS)]. Diagnostica. 1996;42:139-156. German. doi:10.1037/t49650-00
45. Schwarzer R, Jerusalem M, eds. Skalen zur Erfassung von Lehrerund Schülermerkmalen. Dokumentation der psychometrischen Verfahren im Rahmen der wissenschaftlichen Begleitung des Modellversuchs Selbstwirksame Schulen [Scales for the Assessment of Teacher and Student Characteristics. Documentation of Psychometric Procedures in the Context of the Scientific Mentoring of the Pilot Project Self-Efficacious Schools]. Freie Universität Berlin; 1999. German.

46. Falkenberg I, McGhee PE, Wild B. Humorfähigkeiten trainieren. Manual für die psychiatrisch-psychotherapeutische Praxis [Training humor skills. A manual for psychiatric and psychotherapeutic practice]. Schattauer; 2013. German.

47. McGhee PE. Humor as Survival Training for a Stressed-Out World: The 7 Humor Habits Program. Authorhouse; 2010.

48. Cohen J. Statistical Power Analysis for the Behavioral Sciences. 2nd ed. Erlbaum; 1988.

49. Landis JR, Koch GG. The measurement of observer agreement for aategorical data. Biometrics. 1977;33(1):159. doi:10.2307/2529310

50. Gander F, Proyer RT, Ruch W. A placebo-controlled online study on potential mediators of a pleasure-based positive psychology intervention: the role of emotional and cognitive components. J Happiness Stud. 2018;19(7):2035-2048. doi:10.1007/s10902-017-9909-3

51. Santos V, Paes F, Pereira V, et al. The role of positive emotion and contributions of positive psychology in depression treatment: systematic review. Clin Pract Epidemiol Ment Heal. 2013;9(1):1221237. doi:10.2174/1745017901309010221

52. Gonot-Schoupinsky FN, Garip G, Sheffield D. Laughter and humour for personal development: a systematic scoping review of the evidence. Eur J Integr Med. 2020;37:101-144. doi:10.1016/j. eujim.2020.101144

53. Bennett PN, Parsons T, Ben-Moshe R, et al. Laughter and humor therapy in dialysis. Semin Dial. 2014;27(5):101-144. doi:10.1111/ sdi. 12194

54. Gonot-Schoupinsky FN, Garip G. Laughter and humour interventions for well-being in older adults: a systematic review and intervention classification. Complement Ther Med. 2018;38:85-91. doi:10.1016/j. ctim.2018.04.009

55. Hofmann J, Platt T, Ruch W, Niewiadomski R, Urbain J. The influence of a virtual companion on amusement when watching funny films. Motiv Emot. 2015;39(3):434 447. doi:10.1007/s11031-0149461-y

56. Papousek I, Schulter G. Effects of a mood-enhancing intervention on subjective well-being and cardiovascular parameters. Int $\mathrm{J}$ Behav Med. 2008;15(4):293-302. doi:10.1080/10705500802365508

57. Wellenzohn S, Proyer RT, Ruch W. Who benefits from humor-based positive psychology interventions? The moderating effects of personality traits and sense of humor. Front Psychol. 2018;9821. doi:10.3389/fpsyg.2018.00821

58. Ruch W, McGhee PE. Humor intervention programs. In: Parks AC, Schueller SM, editors. The Wiley Blackwell Handbook of Positive Psychological Interventions. John Wiley \& Sons, Ltd; 2014;179-193

59. Bundesinstitut für Arzneimittel und Medizinpodukte (BfArM). Operationen- und Prozedurenschlüssel Version 2021 [Federal Insitute for Drugs and Medical Devices. German Procedure Classification Version]. 2021. Available from: https://www.dimdi.de/ static/de/klassifikationen/ops/kode-suche/opshtml2021/. Accessed February 28, 2021. German. 


\section{Publish your work in this journal}

The Journal of Pain Research is an international, peer reviewed, open access, online journal that welcomes laboratory and clinical findings in the fields of pain research and the prevention and management of pain Original research, reviews, symposium reports, hypothesis formation and commentaries are all considered for publication. The manuscript management system is completely online and includes a very quick and fair peer-review system, which is all easy to use. Visit http:// www.dovepress.com/testimonials.php to read real quotes from published authors.

Submit your manuscript here: https://www.dovepress.com/journal-of-pain-research-journal 